\title{
Diode Laser-assisted Periodontal Esthetic Therapy
}

\author{
${ }^{1}$ Burnice NK Chellathurai, ${ }^{2}$ Selvakumar Jayakumar, ${ }^{3} \mathrm{CS}$ Krishnan, ${ }^{4}$ Aazam Ahammed
}

\begin{abstract}
The diode laser has become an important dental armamentarium because of its exceptional ease of use and affordability. The lasers have many advantages with regard to periodontal treatment. For all soft tissue procedures, the diode laser functions as the handpiece, just like a dental handpiece for all hard tissue procedures. The main advantages of the diode laser for soft tissue applications are precise surgical procedure, bloodless surgery, sterilization of the surgical site, least possible swelling and scarring, negligible suturing, and practically no pain during and after surgery.

In cosmetic dentistry, providing a desirable smile is one of the main concerns. Hyperpigmentation is one of the esthetic concerns especially in patients with black and discolored gums. Gingival depigmentation can be performed by means of surgical blade, electrosurgery, coarse diamond bur, cryosurgery, or lasers. Bearing in mind the advantages of lasers over other modalities of treatment, the present article will target on the management of such a case using diode lasers.
\end{abstract}

Keywords: Depigmentation, Diode laser, Esthetic surgery.

How to cite this article: Chellathurai BNK, Jayakumar S, Krishnan CS, Ahammed A. Diode Laser-assisted Periodontal Esthetic Therapy. Int J Laser Dent 2015;5(1):29-32.

Source of support: Nil

Conflict of interest: None

\section{INTRODUCTION}

Gingival hyperpigmentation is removed or reduced by a periodontal plastic surgical procedure known as gingival depigmentation. ${ }^{1}$ Patient demand for improved esthetics is the first and foremost indication for depigmentation. Elimination of these melanotic areas can be done by scraping, free gingival autografting, cryosurgery, electrosurgery, and various types of lasers. ${ }^{2}$ Clinical experience and individual preferences play a vital role in the selection of the technique. ${ }^{3}$

\section{LASER IN DENTISTRY}

Lasers have been used in dental treatments for more than 25 years. Unfortunately, they were largely ignored

\footnotetext{
${ }^{1}$ Senior Lecturer, ${ }^{2}$ Professor, ${ }^{3}$ Reader, ${ }^{4}$ Private Practioner

${ }^{1-4}$ Department of Periodontology and Implantology, Madha Dental College and Hospital, Chennai, Tamil Nadu, India
}

Corresponding Author: Burnice NK Chellathurai, Senior Lecturer, Department of Periodontology and Implantology Madha Dental College and Hospital, Chennai, Tamil Nadu India, Phone: +914424780736, e-mail: dr burnice@yahoo.co.in as they were regarded as large, unwieldy, expensive, and difficult to use machines. Certain lasers are used specifically for soft tissue treatments, namely, the $\mathrm{CO}_{2}$, neodymium-doped yttrium aluminum garnet (Nd:YAG), and diode lasers. Others lasers that are used for both soft and hard tissue applications include erbium (Er), chromium:yttrium scandium gallium garnet (Cr:YSGG), and erbium:yttrium aluminum garnet (Er:YAG) lasers.

\section{LASERS IN PERIODONTAL TREATMENT}

Many of the lasers have been shown to aid in periodontal treatments. Laser irradiation has been used to serve as an alternative or as an adjunctive treatment to conventional mechanical periodontal therapy. Among the lasers used in periodontal treatment, the semiconductor diode laser has been proved to be the ideal soft tissue handpiece due to its exceptional ease of use and affordability. The key advantages with regard to periodontal treatment include good absorption by melanin, hemoglobin, and other chromophores present in periodontal disease, specifically targeting the unhealthy gingival tissues. There are two types of diode lasers: The high-level diode laser (which emits high levels of light energy) and the low-level diode laser (which emits low intensity light energy). The treatments commonly done with the help of diode lasers include treatment of periodontal pockets, as an adjunct to scaling and root planing (SRP), melanin depigmentation, gingivectomy, crown lengthening, management of endo-perio lesions, frenectomy, etc.

This article seeks to evaluate the effectiveness of diode lasers in soft tissue treatments.

\section{CASE REPORT}

A 23-year-old male patient reported to the outpatient section of the department in our college with the chief complaint of discolored gingiva surrounding all his teeth, which he had been noticing since 2 years (Figs $1 \mathrm{~A}$ to $\mathrm{C}$ ). The patient was explained about the treatment options and informed that after depigmentation, melanin pigmentation would tend to reappear and as gingivectomy would also be carried out simultaneously, the overall appearance would be worth doing it. Gingivoplasty was designed using diode laser under local anaesthesia. Diode laser having a thin flexible light guide with a diameter of $0.4 \mathrm{~mm}$ and a wavelength of $810 \mathrm{~nm}$ at a power of 0.8 $\mathrm{W}$ was used for lasing. 


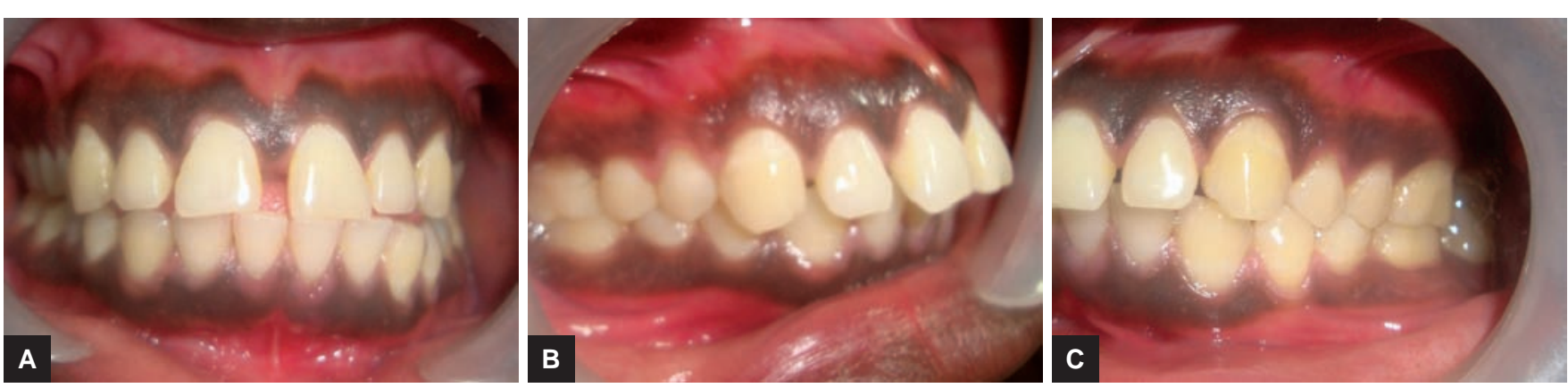

Figs 1A to C: Preoperative photographs of the patient
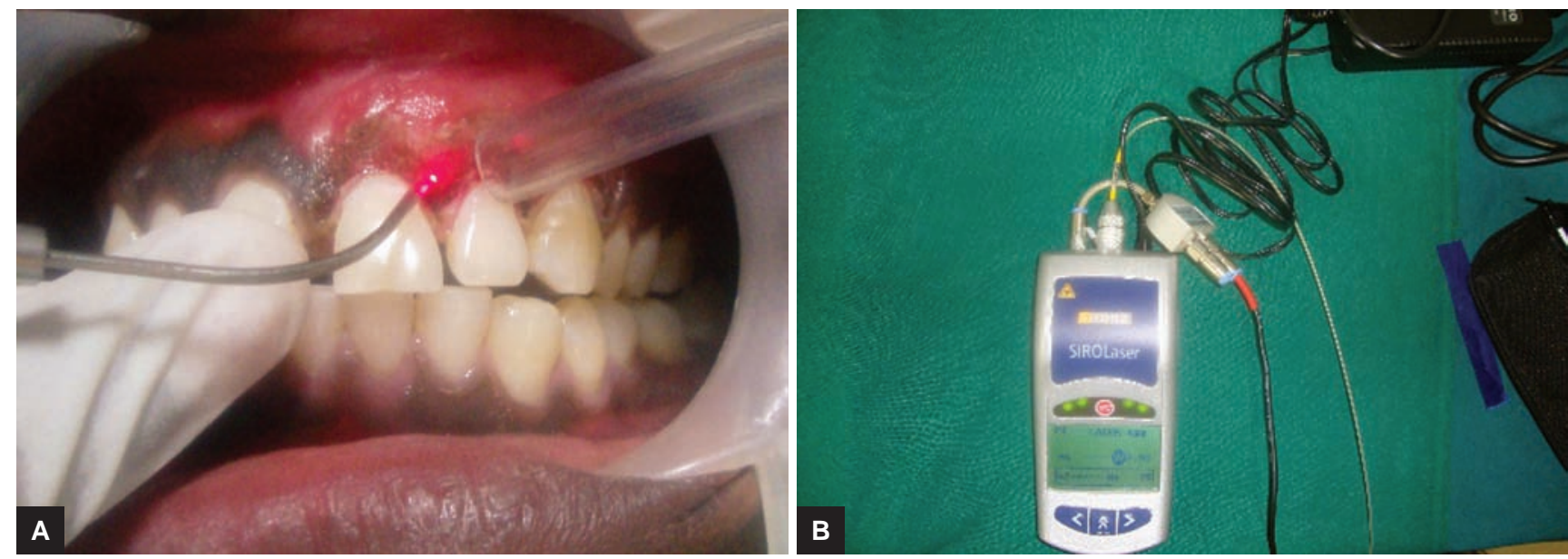

Figs $2 \mathrm{~A}$ and $\mathrm{B}$ : Lasing of the second quadrant using diode laser

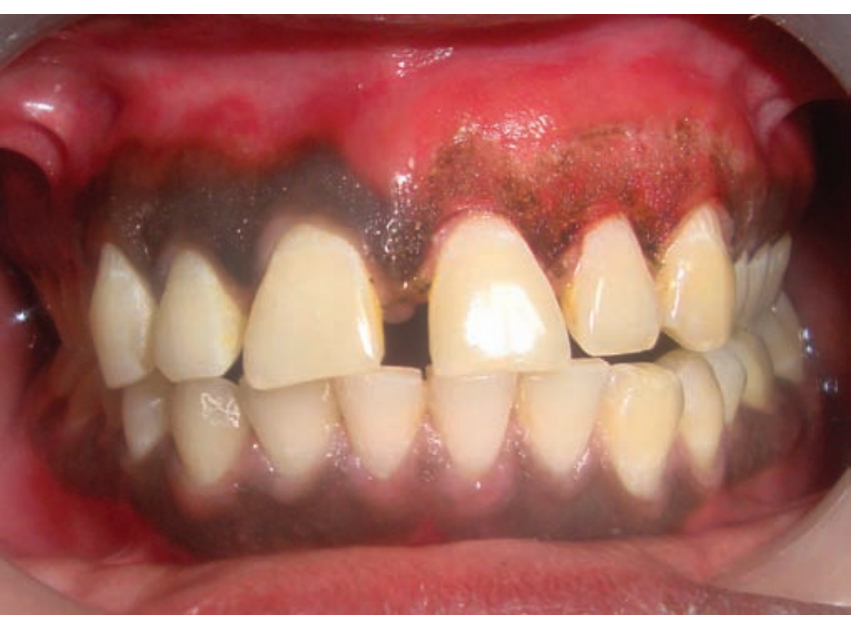

Fig. 3: Immediate postoperative photograph of the second quadrant

Each tooth was subdivided into four sites, each of which was lased separately as follows: Before placing the tip into the area, the laser was "initiated" with black articulating tape (Accufilm II, Parkell). This helped the laser energy to be pinpointed to the end portion of the fiber optic tip making it possible to emit laser energy only to the intended areas rather than laterally. The diode laser was set at the lowest possible setting.

The tip of the optical fiber was inserted. Illumination was started by keeping optical fiber perpendicular to the root surface. The fiber was passed both in vertical and

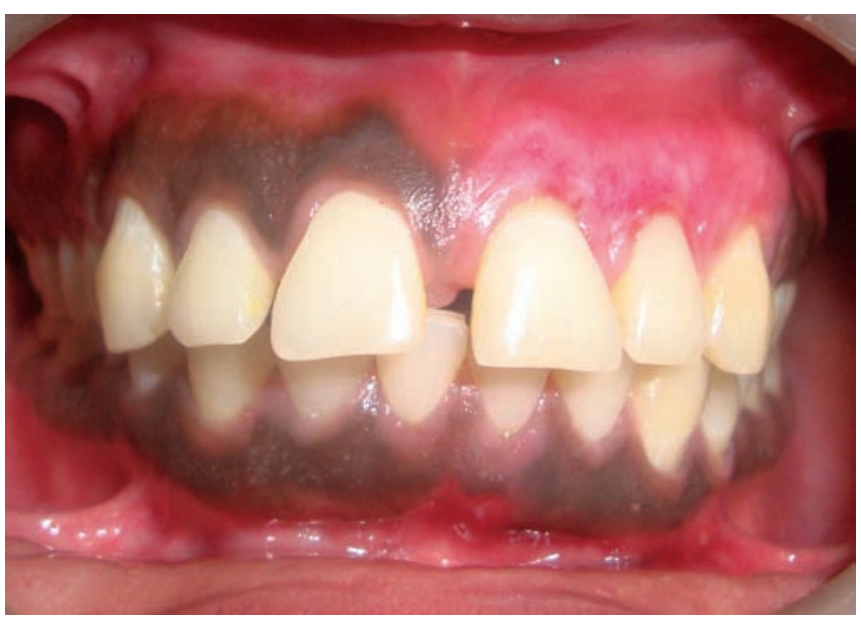

Fig. 4: One-week postoperative photograph of the second quadrant

horizontal directions thereby covering both the epithelial surface and connective tissues (Figs 2A and B). Vaporizing the necrotized tissues eliminated the bacterial flora. The duration of lasing depended on the depth. The depth in millimeter $(\mathrm{mm})$ corresponds to the exposure time in seconds. Therapy was terminated when there was light bleeding (Fig. 3).

\section{POSTOPERATIVE HEALING}

Wound healing was uneventful when reviewed after a week (Fig. 4). Procedure was carried out for remaining 


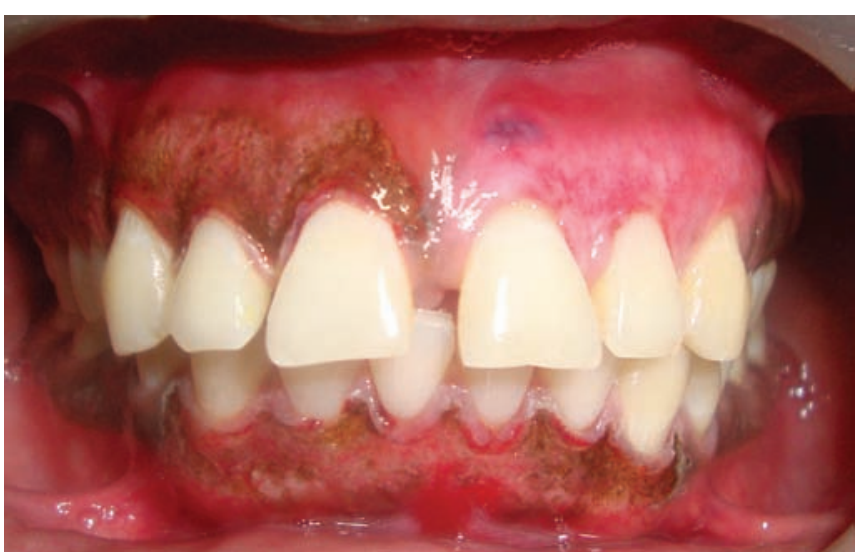

Fig. 5: Immediate postoperative photograph of the remaining quadrants

quadrants (Fig. 5) and observed after weeks (Fig. 6). Diode laser was highly effective for soft tissue applications including incision, hemostasis, and coagulation. The advantages of laser $v s$ the scalpel blade included a bloodless operating field, least possible swelling and scarring, and practically much less or no postsurgical pain. ${ }^{4,5}$ An ideal environment for periodontal healing included a smooth, clean soft tissue surface, a clean, calculusfree hard tissue surface, no pathogenic bacteria, and biostimulation. Biostimulation was performed finally using the diode laser that aided in healing the damaged cells that line the wall of the inner epithelium. ${ }^{6-9}$

The surface produced by the laser surgical procedure healed favorably as an open wound, without the need for sutures or any surgical dressings. ${ }^{10}$ Owing to the effective bactericidal action of lasers on periodontal pathogens, the use of antibiotics as an adjunctive is not necessary, ${ }^{11}$ thereby eliminating the problem of bacterial resistance and systemic side effects engendered by antibiotic use. ${ }^{12}$ A faster and more comfortable wound healing would have occurred if the diode laser were used in conjunction with SRP.

Patient was instructed to avoid certain foods for at least 24 hours, including crunchy or spicy foods, foods with tiny seeds, and foods that may lodge into the spaces created by the procedure. Patient was further asked to avoid smoking for at least 24 hours, rinse with warm salt water at least twice daily for 3 days posttreatment, and avoid flossing and hard brushing for 48 hours posttreatment. If the patient experienced discomfort after the procedure was completed, ibuprofen or a similar pain reliever was prescribed, but typically this was not necessary. After the initial 48 hours, patient was asked to brush and floss according to normal routine.

\section{DISCUSSION}

Among the different methods, laser application showed promising results. It was the least invasive and predict-

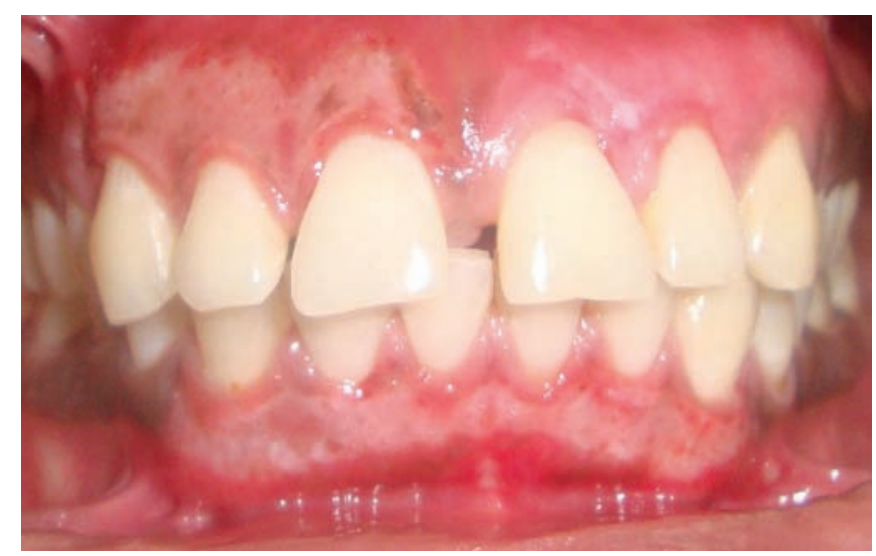

Fig. 6: One-week postoperative photograph of the remaining quadrants

able method of performing this procedure. ${ }^{13}$ Diode laser energy is thermal and it actually vaporizes the targeted diseased tissue. Use of diode laser offers two distinct advantages over scalpel procedures. First is the extreme precision for removal of only targeted tissue and second, laser provides simultaneous coagulation of blood vessels, providing an optimal environment for speedy healing. The diode laser is well absorbed by melanin, hemoglobin, and other chromophores that are present in periodontal diseases. ${ }^{14}$ The laser energy is transferred via a thin fiber that can easily penetrate into the specifically targeted unhealthy gingival tissues to deliver its therapeutic effects. The protein coagulum formed on the wound surface after laser surgery acts as a biological dressing to reduce the postoperative pain. Another factor for pain reduction after surgery is the sealing of the ends of the sensory nerve. ${ }^{15,16}$ Melanin granules synthesized by melanocytes when transferred to the keratinocytes produce melanin pigmentation in gingiva. ${ }^{17}$ This makes the recurrence of pigmentation inevitable. The recurrence has been reported from 24 hours to 8 years following surgery. ${ }^{18}$

\section{CONCLUSION}

The above-mentioned results rationalize the interest in the application of the laser in general to the field of periodontology. Because the effects of laser treatment on tissues basically depend on the wavelength, pulse energy, frequency, and spot size used, when these factors are taken into account, diode laser can be considered as an interesting alternative to conventional treatment. Furthermore, among the various laser systems, diode laser radiation is absorbed by the superficial layer, while the other laser systems are absorbed by deeper tissue layers and thus have a better effect on sites. We have the tools and protocol now to treat our patients with an effective procedure that they are ready to accept. 


\section{REFERENCES}

1. Almas K, Sadiq W. Surgical treatment of melanin-pigmented gingiva: an esthetic approach. Indian J Dent Res 2002 AprJun;13(2):70-73.

2. Deepak P, Sunil S, Mishra R, Sheshadri. Treatment of gingival pigmentation: a case series. Indian J Dent Res 2005 Oct-Dec;16(4):171-176.

3. Cicek Y, Ertas U. The normal and pathological pigmentation of oral mucous membrane: a review. J Contemp Dent Pract 2003 Aug 15;4(3):76-86.

4. Pick RM, Colvard MD. Current status of lasers in soft tissue dental surgery. J Periodontol 1993 Jul;64(7):589-602.

5. Romanos G, Nentwig GH. Diode laser $(980 \mathrm{~nm})$ in oral and maxiofacial surgical procedures: clinical observations based on clinical applications. J Clin Laser Med Surg 1999 Oct;17(5): 193-197.

6. Hamajima S, Hiratsuka K, Kiyama-Kishikawa M, Tagawa T, Kawahara M, Ohta M, Sasahara H, Abiko Y. Effect of lowlevel laser irradiation on osteoglycin gene expression in osteoblasts. Lasers Med Sci 2003;18(2):78-82.

7. Trelles MA, Mayayo E. Bone fracture consolidates faster with low-power laser. Lasers Surg Med 1987;7(1):36-45.

8. Takeda Y. Irradiation effect of low-energy laser on alveolar bone after tooth extraction. Experimental study in rats. Int J Oral Maxillofac Surg 1988 Dec;17(6):388-391.
9. Dortbudak O, Haas R, Mallath-Pokorny G. Biostimulation of bone marrow cells with a diode soft laser. Clin Oral Implants Res 2000 Dec;11(6):540-545.

10. Aoki A, Mizutani K, Takasaki AA, Sasaki KM, Nagai S, Schwarz F, Yoshida I, Eguro T, Zeredo JL, Izumi Y. Current status of clinical laser applications in periodontal therapy. Gen Dent 2008 Nov-Dec;56(7):674-687.

11. Ciancio SG. Effect of a diode laser on Actinobacillus actinomycetemcomitans. Biol Ther Dent 2006 Nov-Dec;22(3):1-2.

12. Harris DM, Yessik M. Therapeutic ratio quantifies laser antisepsis: ablation of Porphyromonas gingivalis with dental lasers. Lasers Surg Med 2004;35(3):206-213.

13. Rowson JE. The contact diode laser: a useful surgical instrument for excising oral lesions. Br J Oral Maxillofac Surg 1995;33:123.

14. Raffetto N. Lasers for initial periodontal therapy. Dent Clin North Am 2004 Oct;48(4):923-936.

15. Lagdive S, Doshi Y, Marawa PP. Management of gingival hyperpigmentation using surgical blade and diode laser therapy: a comparative study. J Oral Laser Appl 2009;9:41-47.

16. Berk G, Atici K, Berk N. Treatment of gingival pigmentation with Er-Cr:YSGG laser. J Oral Laser Appl 2005;5(4):249-253.

17. Lerner AB, Fitzpatric TB. Biochemistry of melanin formation. Physiol Rev 1950 Jan;30(1):91-126.

18. Kher U. Clinical applications of soft tissue diode lasers. Gonion 2010;1:56-60. 